\title{
UNA CRÍTICA A LA HISTORIA DE LAS IDEAS LATINOAMERICANA PROPÓSITO DE LAS OBRAS QUE ESTUDIARON EL PENSAMIENTO POLÍTICO DE JUAN BAUTISTA ALBERDI. ANÁLISIS DE LA TRADICIÓN REPUBLICANA DE NATALIO BOTANA
}

\author{
Luis Ignacio Garcia Sigman ${ }^{1}$ \\ Universidad de Belgrano - CONICET, Argentina
}

http://dx.doi.org/10.5209/rev_NOMA.2013.42342

\begin{abstract}
Resumen.- Este trabajo forma parte de una investigación más amplia que se propone establecer que las obras que analizaron el pensamiento político de Juan Bautista Alberdi, por lo menos un número muy significativo de las mismas, tienen, al haber asumido en enfoque metodológico característico de la historia de las ideas latinoamericana, un carácter predominantemente mitológico. En particular, el presente artículo se plantea: a. presentar la lógica del razonamiento que permite sostener que la adopción del método propio de la historia de las ideas de tal región condujo, en gran medida, a la elaboración de estudios con el citado rasgo mitológico. Dicha tarea se realizará, principalmente, conjugando las reflexiones metodológicas de Quentin Skinner con las de Elías Palti; y b. aplicar dicha propuesta al análisis de La tradición republicana de Natalio Botana; uno de los más significativos estudios dedicados al análisis de la obra del publicista tucumano.
\end{abstract}

Palabras clave.- historia de las ideas, historia intelectual, Alberdi, Botana

\section{A critique of the Latinamerican history of ideas purpose of the works that studied Juan Bautista Alberdi's political thought. Analysis of Natalio Botana's The Republican Tradition}

\begin{abstract}
Abtract.-_This paper is part of a larger research that seeks to establish that the works that analyzed the political thought of Juan Bautista Alberdi, at least a significant number of them, are, having assumed the characteristic methodological approach of the history of ideas in Latin America, predominantly mythological. In particular, this article seeks: a. to present the logic which shows that the adoption of the method of the history of ideas of such region led, to a large extent, to the development of studies with the aforementioned mythological trait. This task will be performed, mainly, by combining the methodological reflections of Quentin Skinner and Elias Palti; and b. to implement this proposal to the analysis of Natalio Botana's The Republican Tradition, one of the most significant studies devoted to the analysis of the work of the tucumano publicist.
\end{abstract}

Keywords.- history of ideas, intellectual history, Alberdi, Botana

\footnotetext{
${ }^{1}$ Licenciado en Ciencia Política (Universidad de Belgrano), candidato a Doctor en Ciencias Política (Universidad de Belgrano), candidato a Doctor en Ciencias Sociales (Universidad de Buenos Aires), docente de teoría política I y II (Universidad de Belgrano), becario de postgrado tipo I del Consejo Nacional de Investigaciones Técnicas y Científicas (CONICET).
} 


\section{Introducción}

Los pensadores argentinos del siglo XIX - en particular, aquellos que se dedicaron a reflexionar sobre la "organización nacional" - concentraron el interés de numerosos científicos sociales. Juan Bautista Alberdi, en particular, fue uno de los que más atracción generó en las sucesivas generaciones de historiadores. Mucho es lo que se ha escrito sobre la obra del publicista tucumano ${ }^{2}$ pero muy poco acerca del enfoque metodológico asumido por la mayoría de tales estudios.

Este trabajo forma parte de una investigación más amplia que se propone configurar un aporte en dicho sentido ${ }^{3}$; el objetivo principal de tal proyecto radica en establecer que las obras que analizaron el pensamiento político de Juan Bautista Alberdi, por lo menos un número muy significativo de las mismas, tienen, al haber asumido en enfoque metodológico característico de las historia de las ideas latinoamericana, un carácter predominantemente mitológico.

En particular, el presente artículo se propone, por un lado, presentar la lógica del argumento que permite sostener que la adopción del método de la historia de las ideas en América Latina condujo, en gran medida, a la elaboración de estudios con el citado rasgo mitológico y, por otro lado, aplicar dicho razonamiento en el análisis de La Tradición Republicana de Natalio Botana. La consecución de dichos propósitos implicará que el trabajo se divida en cuatro secciones; las primeras tres estarán orientadas a la formulación de la propuesta teórico - metodológica mientras que la última se concentrará en el examen de la citada obra del politólogo argentino.

En primer lugar, se analizarán los supuestos alrededor de los que, según Skinner, se estructuró la propuesta metodológica de la historia de las ideas y también las

\footnotetext{
${ }^{2}$ Algunas de las obras más significativas al respecto son las siguientes: Alberini, C. (1934). La metafísica de Alberdi. Archivos de la Universidad de Buenos Aires, año IX, lomo IX; Botana, N. (2005). La tradición republicana. Alberdi, Sarmiento y las ideas políticas de su tiempo. Buenos Aires: Sudamericana; Canal Feijoo, B. (1955). Constitución y Revolución. Buenos Aires: FCE; Chávez, F. (1982). Historicismo e iluminismo en la cultura argentina. Buenos Aires: CEAL; Ciapuscio, H. (1985). El pensamiento filosófico - político de Alberdi. Buenos Aires: ECA; Dotti, J. E. (1990). Las vetas del texto. Una lectura filosófica de Alberdi, los positivistas, Juan B. Justo. Buenos Aires: Puntosur; Feinmann, J.P. (2004). Filosofía y nación. Buenos Aires: Seix Barral; Garcia Merou, M. (1916). Alberdi. Ensayo crítico. Buenos Aires: La Cultura Argentina; Groussac, P. (1918). Las Bases de Alberdi. En Groussac, P. Estudios de historia argentina. Buenos Aires: Jesús Menéndez; Halperin Donghi, T. (2005). Una nación para el desierto argentino. Buenos Aires: Prometeo; Irazusta, J. (1952). Ensayos históricos. Buenos Aires: La voz del Plata; Mayer, J. (1963). Alberdi y su tiempo. Buenos Aires: Eudeba; Murray, L. A. (1960). Pro y contra de Alberdi. Buenos Aires: Editorial Coyoacán; Orgaz, R. (1937). Alberdi y el historicismo. Córdoba: Imprenta Rossi; Pereyra, C. (s/fecha). El pensamiento político de Alberdi. Madrid: Editorial América; Popolizio, E. (1945). Alberdi. Buenos Aires: Losada; Romero, J.L. (2005). Las ideas políticas en la Argentina. Buenos Aires: FCE; Terán, O. (2008). Historia de las ideas en la Argentina. Diez lecciones iniciales, 1810 - 1980. Buenos Aires: Siglo Veintiuno; Terán, O. (2004). Las palabras ausentes: para leer los Escritos Póstumos de Alberdi. Buenos Aires: FCE.

${ }^{3}$ Se hace referencia a la tesis de Doctorado (en el marco del Programa de Doctorado en Ciencias Sociales de la Universidad de Buenos Aires) en la que el autor del artículo se encuentra trabajando en estos momentos.
} 
críticas que este historiador británico le hizo a dicho enfoque. Skinner sostiene que los científicos sociales que trabajaron con el enfoque metodológico de la historia de las ideas asumieron que existían ciertos "temas perennes" 4 en la historia del pensamiento político y también que los diferentes autores debían realizar contribuciones a aquellos. En este sentido, la labor del historiador pasó a ser el estudio de lo que los teóricos "decían" acerca de esos "conceptos fundamentales"; las obras de las que extraían dichos aportes fueron consideradas, por estos científicos sociales, como entidades autosuficientes (Skinner, 2007: 109 - 110). Estos estudios, sostiene Skinner, tuvieron, al trabajar de tal modo, un carácter mitológico y no histórico que se expresó de cuatro modos diferentes (aunque no excluyentes): mitología de las doctrinas, mitología de la coherencia, mitología de la prolepsis, mitología del localismo (Skinner, 2007: 111).

En segundo lugar, se sostendrá, siguiendo a Palti, que el rasgo específico que caracterizó a los trabajos que adoptaron el enfoque de la historia de las ideas en América Latina fue el de estructurarse alrededor de tipos ideales antitéticos ${ }^{5}$ no problematizados ${ }^{6}$. Se comenzará indicando que existieron, tal como lo sostiene el historiador argentino y Polgovsky Ezcurra, tres etapas en el desarrollo de la disciplina en la región. En un primer momento, los trabajos se organizaron alrededor del método genealógico ${ }^{7}$. Los historiadores partieron de alternativas dicotómicas y se propusieron distinguir las diferentes ideas de los textos analizados para, posteriormente, clasificarlas en el marco de tales opciones antitéticas. De este modo, las posibilidades, a la hora de establecer las filiaciones de dichas ideas, quedaron reducidas a tres: se podía pertenecer a alguno de los extremos o bien ocupar un lugar intermedio entre ambos polos (Palti, 2008:23 26; Polgovsky Ezcurra, 2010).

Este método tuvo, según Palti, dos grandes limitaciones de las que derivaron los equívocos en los que incurrieron los historiadores que lo utilizan para guiar sus trabajos. Por un lado, el modelo genealógico no tuvo en cuenta que las ideas podían manifestarse en el marco de diferentes lenguajes políticos y, por otro lado, no contempló que los tipos ideales, aquellos que construyó para utilizar como referencia a la hora de catalogar las ideas halladas en los textos, no aceptan, en

\footnotetext{
${ }^{4}$ Se utilizarán, siguiendo el criterio adoptado por Skinner, de forma intercambiable las siguientes expresiones: tema perenne, concepto fundamental, idea perenne, cuestión permanente, tema obligatorio, problema atemporal e idea - unidad (Skinner, 2007).

${ }^{5}$ Se utilizarán, a partir de ahora y de modo equivalente, las siguientes expresiones: cadenas conceptuales antagónicas/antitéticas/dicotómicas, corrientes antagónicas/antitéticas/dicotómicas, alternativas antagónicas/antitéticas/dicotómicas, tipos ideales antagónicas/antitéticas/dicotómicas, opciones antagónicas/antitéticas/dicotómicas.

${ }^{6} \mathrm{Al}$ hacer referencia a esta idea, se utilizarán, asumiendo el criterio propuesto por Palti, de forma equivalente las siguientes expresiones: no problematizadas/os - dada/os - no cuestionadas/os lógicamente integrados - absolutamente racionales - completamente autoconsistentes (Palti, 2008).

${ }^{7}$ Palti no resulta del todo claro en relación con la inclusión de tal período en el marco de la historia de las ideas latinoamericana. En algunos trabajos considera que la historia de la disciplina comienza en este período (Palti, 2008) y, en otros estudios, que se inaugura con la segunda etapa expuesta en este artículo (Palti, 2007). Su inclusión o exclusión no amenazan, de ningún modo, el argumento que se trata de proponer. En este caso, se sigue el criterio de la inclusión.
} 
tanto también son constructos históricos, una definición unívoca, universal o necesaria (Palti, 2008: 24 - 25).

En un segundo momento, los estudios comenzaron a adoptar el esquema de modelos y desviaciones. Los historiadores que analizaron las obras de los autores de la región asumieron, sostiene Palti, que éstas sólo adquirían valor en tanto que encarnaban versiones desviadas de las ideas europeas (Palti, 2007:22). Dicha torsión semántica derivaba, según estos científicos sociales, del impacto que sufrían los tipos ideales europeos al entrar en contacto con las circunstancias nacionales de los autores locales cuyos textos estudiaban (Palti, 2007:23). Los historiadores articularon sus obras alrededor de alternativas dicotómicas en el marco de las cuales clasificaron las obras de los teóricos latinoamericanos. Las opciones quedaron prefijadas de antemano, todo autor podía acercarse a alguno de los extremos 0 bien ubicarse en algún punto intermedio entre ambas alternativas antagónicas (Palti, 2008:22 - 23). Al trabajar de este modo, sostiene Palti, los historiadores promovieron una visión formalista y teleológica de la historia intelectual de la región (Palti, 2008:32 - 33).

En un tercer momento, comenzaron a surgir una serie de trabajos que se propusieron criticar y superar, en general, el enfoque tradicional de la historia de las ideas y, en particular, el esquema de modelos y desviaciones; entre ellos, se destacan, específicamente, los trabajos de Roberto Sschwarz y los estudios revisionistas de Charles Hale y Francoi - Xavier Guerra (Palti, 2007: 27 - 39, 44 51; Polgovsky Ezcurra, 2010:s/d).

Palti reconoce que dichos trabajos lograron desestabilizar los supuestos de la tradicional perspectiva metodológica de la historia de las ideas pero también señala que no pudieron trascender dicho enfoque (y siguieron moviéndose dentro de él) en la medida en que asumieron muchos de sus supuestos y reprodujeron, en consecuencia, sus limitaciones; en particular, en relación con lo que interesa a este trabajo, debe destacarse que tales obras siguieron articulándose en torno a opciones dicotómicas (Palti, 2007:27 - 39. 47 - 51; Palti, 2005:23 - 32; Palti, 2005:82) ${ }^{8}$.

Luego se volverá sobre la idea central de la sección, es decir, que los historiadores que adhirieron al enfoque metodológico de la historia de las ideas para estudiar el pensamiento político en América Latina, en cualquiera de los tres momentos de su desarrollo, se caracterizaron por articular sus obras alrededor de opciones antitéticas. Por último se sostendrá que la mayoría de dichos estudios no se organizaron sólo alrededor de una dicotomía sino que lo hicieron alrededor de cadenas conceptuales antagónicas.

\footnotetext{
${ }^{8}$ Cfr. Polgovsky Ezcurra, M. (2010). La historia intelectual latinoamericana en la era del giro lingüístico. Nuevo Mundo Mundos Nuevos, s/d. La autora considera que tales trabajos no pueden seguir siendo inscriptos en el marco de la historia de las ideas. La obra de Francoi - Xavier Guerra es considerada por esta científica social como la culminación de un proceso orientado al desmantelamiento del tradicional enfoque de la historia de las ideas que había comenzado con los estudios de Roberto Schwarz y continuado con los trabajos de Charles Hale.
} 
En tercer lugar, se sostendrá que los trabajos que asumieron la perspectiva metodológica que, según Palti, caracterizó a la historia de las ideas latinoamericana tienen un carácter predominantemente mitológico. El argumento será doble. Por un lado, se considera que los historiadores, al organizar sus estudios alrededor de alternativas antitéticas, no sólo se preocuparon por analizar el lugar que cada autor analizado ocupaba en dicho esquema sino que convirtieron las cadenas conceptuales antagónicas en los "temas fundamentales" sobre los que esperaron que los escritores estudiados realizaran una significativa contribución.

Por otro lado, se sostiene que la legitimidad de la afirmación realizada deriva de que tales trabajos, cuya especificidad se indicó previamente, compartieron, al asumir un enfoque que se caracteriza por ser la manifestación local de una tendencia metodológica más amplia, los supuestos alrededor de los que se organizan los trabajos de los historiadores que se acercan a los textos bajo la influencia del paradigma de la historia de las ideas.

De este modo, el trabajo de estos científicos sociales consistió en estudiar lo que los autores latinoamericanos "decían" sobre la alternativa antagónica con la que cada uno de ellos lo vinculaba. Si bien resulta importante indicar que no todos, al realizar esta tarea, consideraron a las obras de los autores de la región como entidades absolutamente autosuficientes, también es importante señalar que, como consecuencia de los límites que el enfoque adoptado les imponía, siguieron pensando en términos de una rígida separación entre texto y contexto y también que no dejaron de concebir a las obras analizadas como meros conjuntos de ideas (Palti, 2009: 16).

Finalmente, se analizará cómo se expresó cada una de las mitologías en el marco de estos trabajos que asumieron como "temas perennes" las diferentes cadenas conceptuales antitéticas alrededor de las que estructuró, cada historiador que trabajó con esta perspectiva metodológica, su estudio sobre las ideas políticas latinoamericanas.

En cuarto lugar, se buscará establecer, partiendo de la propuesta teórico metodológica reseñada en las secciones anteriores, si La tradición republicana de Natalio Botana, una de las más significativas obras que se preocuparon por analizar el pensamiento político de Alberdi, asumió el enfoque que caracteriza a la historia de las ideas latinoamericanas $y$, por ende, tuvo un carácter predominantemente mitológico. Realizar dichas tareas implicará realizar una triple operación. En un primer momento, se buscarán analizar si el autor estructuró su trabajo alrededor de cadenas conceptuales antagónicas y también si esperó, a al acercarse a los textos de los publicistas que analizó, que hicieran significativas contribuciones a dichas alternativas. En un segundo momento, se tratará de estudiar, de haberse logrado el punto anterior, el lugar que se le adjudicó a Alberdi en el marco de dichas alternativas antitéticas; esto permitirá establecer el aporte que, según el autor, realizó el publicista tucumano a la opción con la que fue asociado. Por último, se analizará, en tanto pueda completarse el segundo momento, el modo en que se manifestaron en dicho trabajo las cuatro mitologías 
indicadas previamente; el espacio que ocupará cada una en el análisis de la citada obra dependerá de la intensidad con que se haya manifestado en cada caso.

\section{La crítica de Skinner a la historia de las ideas}

En la presente sección se estudiarán los principios en torno a los cuales se estructuró, según Skinner, en enfoque metodológico de la historia de las ideas y también se señalarán las debilidades que caracterizaron a los resultados que obtuvieron, según el historiador inglés, los estudios que asumieron, al acercarse a las obras del pasado, dicha perspectiva de trabajo.

\section{Historia de las ideas, una crítica desde la nueva historia intelectual}

Las reflexiones alrededor de las que se estructuró la nueva historia intelectual son el resultado de la insatisfacción generada por los métodos propuestos por la tradicional historia de las ideas, tanto en la versión norteamericana de la History of ideas de Arthur Lovejoy como en la modalidad alemana de Ideengeschichte de Friedrich Meinecke (Fernandez Sebastian, 2002: 334).

Como resultado de ese descontento surgieron, a partir la segunda mitad de la década del sesenta del siglo pasado, una serie de desarrollos teóricos orientados a configurarse como alternativas al método tradicional. Son tres las principales corrientes que configuraron la nueva historia intelectual. En primer lugar, la Escuela de Cambridge, articulada en torno a los trabajos de Quentin Skinner y J. G. A Pocock; en segundo lugar, la Begriffsgeschichte o historia de los conceptos elaborada a partir de los estudios de Reinhart Koselleck y, por último, la escuela francesa cuyo más destacado exponente es Pierre Rosanvallon (Fernandez Sebastián, 2002: 334 -348; Palti, 2009: 15; Palti, 2005: 63 - 64).

En particular, este trabajo centrará su atención en las propuestas de Skinner. El historiador inglés fue, de los diferentes teóricos que formaron parte de esta tendencia que renovó la disciplina, el que mostró mayor preocupación por criticar el enfoque metodológico que querían trascender y también por explicitar detalladamente los principales lineamientos del que propuso (Silva, 2009). Tal esfuerzo relativo al análisis de los métodos hace que los aportes de Skinner resulten sumamente valiosos para un trabajo que se inscribe en el marco de un proyecto que se propone criticar la perspectiva metodológica asumida por una serie de estudios dedicados al pensamiento político de Juan Bautista Alberdi.

En relación con el enfoque metodológico de la historia de las ideas ${ }^{9}$, Skinner sostiene que los científicos que asumieron dicha perspectiva para trabajar

\footnotetext{
${ }^{9}$ Debe aclararse que las críticas de Skinner a los métodos tradicionales no se circunscriben a los enfoques textualistas sino que también alcanzan a las perspectivas contextualistas. Este trabajo sólo se preocupa por las primeras en tanto dicha propuesta, la textualista, fue la privilegiada, como se verá en la sección siguiente al presentar el análisis que Palti realiza sobre la historia de las
} 
consideraron que existían ciertos "problemas perennes" en la historia del pensamiento político acerca de los cuales realizaron aportes relevantes los textos clásicos. La tarea del historiador radica, según este enfoque, en estudiar lo que cada una de estas obras clásicas "decía" acerca de esas "cuestiones permanentes" considerando a los textos como entidades "autosuficientes" (Skinner, 2007:109 - 110).

Los trabajos que adoptaron este enfoque metodológico no pueden ser considerados, según Skinner, como historias sino como mitologías. En este sentido, el historiador inglés distingue cuatro tipos de mitologías en las que incurrieron los autores inscriptos dentro de la corriente que critica: mitología de las doctrinas, mitología de la coherencia, mitología de la prolepsis y mitología del localismo (Skinner, 2007:111).

\section{Mitología de las doctrinas}

Los historiadores de las ideas políticas asumen, cuando se acercan al estudio de los textos, que todos los autores clásicos han enunciado una doctrina sobre los temas perennes que configuran la disciplina. Existe un paso muy corto, sostiene el historiador inglés, entre trabajar con este paradigma y encontrar las doctrinas de un determinado autor sobre los temas obligatorios. Skinner sostiene que esta mitología puede asumir, principalmente, dos formas de expresión (Skinner, 2007:114).

La primera de ellas radica en que el historiador, convencido de que todos los autores realizaron algún aporte o propusieron una doctrina acerca de los problemas perennes de la disciplina, convierta ciertos comentarios dispersos o absolutamente circunstanciales de un teórico en su doctrina sobre alguno de los conceptos fundamentales (Skinner, 2007:114).

A su vez, este modo de manifestación de la presente mitología tiene lugar de dos maneras alternativas. Por un lado, el historiador, en particular los que escriben biografías intelectuales o historias sinópticas del pensamiento, pueden "encontrar", a partir de cierta familiaridad terminológica que pueda existir entre las expresiones de los autores que analizan y los conceptos fundamentales de la disciplina, que estos escritores con los que están trabajando realizaron un aporte a determinado tema obligatorio sin preguntarse si tuvieron (o pudieron haber tenido) la intención de hacerlo (Skinner, 2007:114 - 115).

Por otro lado, los científicos sociales, generalmente los que adscriben al método propuesto por Arthur Lovejoy, parten de la definición de una determinada idea perenne y se acercan a los textos clásicos con el objetivo de descubrir qué dijo

ideas en América Latina, por los trabajos que buscan analizarse. Existen diferentes trabajos que analizan ambas dimensiones críticas del pensamiento de Skinner, pueden destacarse: Silva R. (2009). Historia intelectual e teoría política. Revista de Sociología Política, vol. 37, núm. 43, 301 318; Silva, R. (2010). O contextualismo linguistico do pensamiento político: Quentin Skinner e o debate metodológico contemporáneo. Dados - Revista de Ciencias Sociales, vol. 53, núm. 2, 299 335; Rabasa Gamboa, E. (2011). La escuela de Cambridge: Historia del pensamiento político. Una búsqueda metodológica. En - claves del pensamiento, año V, núm. 9, 157 - 180. Silva, Mexicano. 
cada uno de los autores acerca de ese concepto fundamental definido a priori (Skinner, 2007: 118 - 119). En este caso, se corren dos riesgos. Por un lado, el tipo ideal puede quedar objetivado; esto hace que se hable de las cuestiones fundamentales como si fueran organismos vivos y también que se los considere como rasgos inmanentes de la historia. Por otro lado, se puede perder de vista, como consecuencia de deificar las ideas, la importancia de los agentes en el desarrollo de cada tema obligatorio (Skinner, 2007:119).

Este reinado de las ideas, propio de la perspectiva de la historia de las ideas practicado por Lovejoy, deriva en dos tipos de absurdos históricos. Por un lado, los historiadores que se preocupan por estudiar la trayectoria de determinados conceptos fundamentales pueden sentirse inclinados, toda vez que consideren que un determinado autor realizó una contribución a tales problemas perennes antes de que asumieran su forma más acabada, a evaluarlos en términos de "anticipaciones" y también a valorarlos en función de su clarividencia. Por otro lado, los científicos sociales que asumen el enfoque propuesto por Lovejoy corren el riesgo de trabar eternos debates en torno a si determinada idea - unidad surgió verdaderamente en un momento dado o a si dicho concepto fundamental se encuentra presente, en su expresión más completa, en la obra de un determinado teórico (Skinner, 2007:121).

La segunda forma que asume la mitología de las doctrinas radica en que el historiador, también partiendo del supuesto de que todos los autores clásicos debieron haber realizado alguna contribución sobre los temas perennes, critica a los teóricos que "omitieron" elaborar una doctrina sobre tales cuestiones fundamentales de la disciplina (Skinner, 2007:122).

Esta manifestación de la mitología señalada puede expresarse de dos maneras diferentes. Por un lado, los historiadores, en los casos en los que los teóricos "omitieron" expresar con claridad sus contribuciones sobre determinado tema perenne que caracteriza a la historia del pensamiento político, les adjudican una doctrina sobre ese problema atemporal siempre que la opinión general de los especialistas en la materia ( $y$ en particular, la suya) considere que resulta adecuado atribuírsela (Skinner, 2007:123).

Por otro lado, el científico social, partiendo del supuesto de que los autores clásicos redactaron sus obras buscando construir la doctrina más acabada sobre determinado tema perenne y realizar la contribución más sistemáticas que eran capaces de brindar sobre algún concepto fundamental, critican a los autores porque lo que volcaron en sus obras no se ajusta a las expectativas con las que se habían acercado a estudiarlas (Skinner, 2007:126).

\section{Mitología de la coherencia}

La mitología de la coherencia postula que los historiadores, al asumir que las disciplina se estructura alrededor de conceptos fundamentales y también que los autores deben realizar contribuciones a éstos, pueden sentirse inclinados a dotar a las obras que analizan, en tanto aportes a los temas perennes, de una coherencia 
y una sistematicidad que, muy probablemente, los autores no tuvieran la intención de conferirles (Skinner, 2007:128).

Los historiadores pueden realizar distintos tipos de estrategias para proteger la coherencia que le impusieron a una determinada obra. En primer lugar, los científicos sociales, con tal de lograr extraer la coherencia de un determinado texto, son capaces de obviar lo que los propios autores dijeron en relación con las intenciones con las que realizaron un determinado trabajo y también de desechar determinados textos de ese teórico en tanto pongan en jaque la coherencia que descubrieron en su obra (Skinner, 2007:132).

En segundo lugar, los historiadores, obsesionados por resguardar la coherencia impuesta a un texto de determinado autor clásico, son incapaces de aceptar que dicho teórico haya incurrido en contradicciones. En este sentido, pasan a considerarlas como "contradicciones aparentes" y buscan resolverlas o reinterpretarlas de tal modo que dejen de representar una amenaza para la coherencia "descubierta" en la obra que se encuentran estudiando. (Skinner, 2007:133).

Por último, debe señalarse que la presente mitología también puede asumir la forma inversa a la que se ha analizado hasta el momento. Los historiadores también critican a los autores que analizan en tanto les resulta imposible, en la medida en la que dichos teóricos escribieron tratando de solucionar diversos problemas de maneras diferentes, "aprehender" la coherencia y la sistematicidad que buscan encontrar sus obras. Tampoco en este caso, existe una preocupación identificar lo que el escritor en cuestión estaba haciendo al escribir lo que escribía (Skinner, 2007:130).

\section{Mitología de la prolepsis}

Los científicos sociales, convencidos de que la historia del pensamiento político se organiza alrededor de ideas perennes y también de que los autores clásicos deben enunciar sus doctrinas sobre aquellos, otorgan significado a determinada obra en tanto la consideran un aporte a alguno de los temas obligatorios (Skinner, 2007:138).

Esta operación implica que el significado de la obra sea el que le atribuye el historiador, en tanto la concibe como una contribución a un particular concepto fundamental de la disciplina, y no el que podría haber tenido para el autor de la misma en términos de identificar lo que estaba haciendo al escribirla (Skinner, 2007:138).

Las explicaciones que estos historiadores postulan sobre los diferentes textos que analizan asumen un carácter teleológico en la medida en que dichas obras sólo adquieren significado en un contexto temporal posterior y en relación con el trabajo del historiador que las estudia; de ningún modo, a la hora de otorgarles un significado, las reinsertan en su contexto intelectual original ni se preocupan por identificar lo que los teóricos que las concibieron estaban haciendo al escribirlas (Skinner, 2007:140). 


\section{Mitología del localismo}

Los historiadores de las ideas políticas articulan sus trabajos asumiendo que la disciplina se estructura alrededor de conceptos fundamentales y también que los diferentes teóricos deben realizar aportes a dichos temas obligatorios. Estos científicos sociales organizan sus esquemas conceptuales, siempre en un contexto temporal posterior al de los autores que analizan y muchas veces en un entorno cultural sumamente diferente al de dichos teóricos, alrededor de la aceptación de tales supuestos. Al hacerlo, estos politólogos pueden, la mayoría de las ocasiones de modo inconsciente, homologar sus criterios de clasificación y discriminación con los de los autores que se encuentran analizando (Skinner, 2007:140).

Al trabajar de este modo, los historiadores pueden cometer dos tipos de errores. En primer lugar, los científicos sociales pueden equivocarse a la hora de establecer alguna referencia de un texto que se encuentren analizando. Los historiadores, en tanto consideren que un teórico realizó una contribución a alguno de los temas fundamentales de la disciplina, pueden sentirse inclinados a "descubrir" semejanzas entre los argumentos de dicho autor y las expresiones de otro escritor que, en el pasado, hubiera realizado, según ellos, un aporte al mismo tema obligatorio. De este modo, los politólogos relacionan a dichos autores en términos de "influencias" sin preguntarse si la intención del primero, al escribir su trabajo, era referirse a las expresiones vertidas por el segundo en su texto (Skinner, 2007:141).

En segundo lugar, los científicos sociales pueden confundir el sentido de la obra que estudien. Los historiadores, asumiendo que todo autor debe realizar un aporte a los temas perennes que configuran la historia del pensamiento político, pueden propender a "encontrar" cierta familiaridad entre los enunciados realizados por el teórico que se encuentra analizando y las diferentes ideas unidad alrededor que considera que se articula la disciplina. Al hacerlo, es probable que utilicen dichos conceptos fundamentales como paradigma para describir tales expresiones. Tampoco en este caso, se preocupan por investigar si era la intención del autor manifestarse en tales términos al escribir el texto que analizan. (Skinner, 2007:143).

\section{Las especificidades de la historia de las ideas en América Latina}

El presente apartado se propone dos objetivos. Por un lado, se buscará explicitar los motivos que permiten sostener que el rasgo característico de los trabajos que asumieron el enfoque metodológico de la historia de las ideas latinoamericana fue el de estructurarse en torno de tipos ideales dicotómicos no problematizados; tal empresa implicará realizar un breve recorrido por los tres períodos que, según Palti, caracterizaron el desenvolvimiento de la disciplina en América Latina. Por 
otro lado, se intentará argumentar que las alternativas antitéticas alrededor de las que se organizaron las obras que trabajaron con el citado enfoque asumieron la forma de cadenas conceptuales antagónicas.

\section{El carácter dicotómico del enfoque metodológico de la historia de las ideas en América Latina}

En el presente apartado se sostendrá, tomando como referencia principal las reflexiones de Palti, que la característica distintiva de los estudios que asumieron la perspectiva metodológica de la historia de las ideas para estudiar los textos políticos concebidos en América Latina fue la de organizarse alrededor de tipos ideales antitéticos no problematizados. El sustento de dicha afirmación deriva del estudio de las características de las diferentes etapas en que puede distinguirse, según el historiador argentino, el desarrollo de la disciplina en la región ${ }^{10}$.

Elías Palti sostiene que pueden destacarse tres momentos en desenvolvimiento de la historia de las ideas políticas latinoamericanas. En una primera etapa, los historiadores asumieron, a la hora de organizar sus trabajos, el método genealógico ${ }^{11}$. Los científicos sociales partieron de opciones antagónicas (ilustración/romanticismo, racionalismo/nacionalismo, libertad de los modernos, libertad de los antiguos, etc.) y se preocuparon por separar las ideas de los diferentes autores estudiados para ubicarlas, posteriormente, en el marco de dicho esquema dicotómico. De este modo, labor de clasificación intelectual de los teóricos estudiados no podía escapar del limitado rango alternativas permitidas por el esquema adoptado: las ideas de un autor podían pertenecer a alguna de las alternativas o bien ocupar un lugar intermedio entre ambas opciones (Palti, 2008:23 - 26).

El historiador argentino encuentra dos debilidades principales al método genealógico. Por un lado, indica que uno de los problemas fundamentales de esta estrategia "radica en el hecho de que las ideas y los conceptos se combinan siempre de modos complejos y cambiantes, cumpliendo funciones diversas y tomando sentidos variables según su contexto de enunciación" (Palti, 2008:24). De este modo, trabajar trazando filiaciones entre ideas y conceptos resulta necesariamente equívoco en tanto toda idea puede manifestarse en el marco de

\footnotetext{
10 También pueden consultarse en relación con el desarrollo y estado actual de la disciplina en América Latina: Polgovsky Ezcurra, M. (2010). La historia intelectual latinoamericana en la era del giro lingüístico. Nuevo Mundo Mundos Nuevos, s/d; Álvarez Solís, A. O. (2011). Conceptualizando América. Historia de los conceptos e ideas fuera de lugar. Nuevo Mundo Mundos Nuevos, s/d; y Palti, J. E. (2009). Historia político - intelectual. Las nuevas tendencias en la historia político intelectual. En Brauer, D. (comp.). La historia desde la teoría. Volumen 2. Un guía de campo por el pensamiento filosófico acerca del sentido de la historia y de conocimiento del pasado (9 - 22). Buenos Aires: Prometeo.

${ }^{11}$ Exponentes típicos de esta perspectiva son: Gaos, J. (1953). En torno a la filosofía mexicana. México D. F.: Porrúa y Obregón; Gaos, J. (1954). Filosofía mexicana de nuestros días. México D. F.: Imprenta Universitaria. Según Palti, en la actualidad, un trabajo que también asumió dicho enfoque es el siguiente: Brena, R. (2006). El primer liberalismo español y los procesos de emancipación de América, 1808-1824: una revisión historiográfica del liberalismo hispánico, México D.F.: El Colegio de México (Palti, 2008:26).
} 
diferentes lenguajes políticos (Palti, 2009:18). Por otro lado, señala que esta estrategia no tiene en cuenta que los propios tipos ideales que se utilizan para realizar las catalogaciones de las ideas de los autores de la región también son construcciones teóricas de carácter histórico y contingente que, por dicha razón, no aceptan definiciones cerradas o universales (Palti, 2008:24 - 25).

En una segunda etapa, los historiadores, señala Palti, comenzaron a organizar sus trabajos a partir de la adopción del esquema de modelos y desviaciones ${ }^{12}$. Estos científicos sociales criticaron al modelo genealógico en tanto creyeron que utilizándolo nada podía aprenderse del específico desarrollo de las ideas políticas en América Latina (Palti, 2008:27). En este sentido, dichos historiadores se enfrentaron con la necesidad de responder un interrogante relativo a su propia pertinencia como actividad intelectual: qué tornaba relevante el estudio de las ideas en una cultura derivativa y de una región periférica cuyos pensadores, tal como asumían estos historiadores, no realizaron ninguna contribución a la historia "universal" de las ideas; y, aun aceptando que pudieran haber realizado algún aporte, consideraban, por un lado, que éste sería ínfimo y, por otro lado, que su descubrimiento nada aportaría a la comprensión de la cultura local (Palti, 2007: 23 $-24)$.

El historiador argentino sostiene que, para estos científicos sociales, lo que otorgó sentido al estudio de las ideas políticas de la región no fue otra cosa que analizar cómo se modificaron las ideas liberales europeas al ser trasplantadas en América Latina. La realización de esta empresa intelectual se realizó, observa Palti, estableciendo un esquema de modelos y desviaciones. Se partió de una serie de tipos ideales (al estilo de las "ideas - unidad" de Lovejoy) y se analizó cómo, al cambiarse el contexto, sufrían desviaciones de sentido. De este modo, sostiene Palti, quedó definido, por un lado, el fundamento de la disciplina y, por otro lado, su principal herramienta metodológica (Palti, 2007: 24; Palti, 2008: 24 - 25; Palti, 2009:19).

De este modo, indica el historiador argentino, la historia de las ideas del siglo XIX en América Latina y, en particular, en la Argentina, al asumir el modelo de los esquemas y desviaciones, se estructuró, del mismo modo que el modelo genealógico, alrededor de alternativas dicotómicas (por ejemplo, modernidad/tradición, individualismo/organicismo, democracia/autoritarismo, etc.). Las opciones quedaron, por tal motivo, prefijadas de antemano; toda obra de un autor latinoamericano que se estudiara podía acercarse más a alguna de los dos tipos ideales o bien podía ocupar algún punto intermedio entre ambos (Palti, 2008: 23; Palti, 2009: 25 - 26).

\footnotetext{
${ }^{12}$ En particular, se destacan, en la creación y difusión del citado esquema, las obras de Leopoldo Zea y, en particular, su trabajo sobre el positivismo mexicano. Pueden consultarse: Zea, L. (1949). Dos etapas del pensamiento en Hispanoamérica: del romanticismo al positivismo. México D.F.: El Colegio de México; Zea, L. (1956). Esquema para una historia de las ideas en Iberoamérica. México D.F: UNAM; Zea, L. (1968). El positivismo en México. México D.F.: FCE; Zea, L. (1985). El positivismo y la circunstancia mexicana. México D.F.: FCE.
} 
Palti también señala que los trabajos que adoptaron el esquema de los modelos y desviaciones incurrieron en dos tipos de absurdos históricos. Por un lado, promovieron un visión formalista de la historia en tanto la historicidad no fue considerada como una dimensión constitutiva de los conceptos sino, en el mejor de los casos, como un rasgo que les viene desde afuera (Palti, 2008:32).

Los historiadores de las ideas asumieron que los "modelos" eran entidades aproblemáticas y dadas que se caracterizaban por ser lógicamente integradas, perfectamente racionales y absolutamente consistentes. La temporalidad de estos conceptos quedó, de este modo, completamente negada. Son entidades que se dieron por sentadas y cuya existencia no se problematizó (Palti, 2008:32).

Estos científicos sociales consideraron que las "desviaciones" resultaron del diálogo que se estableció entre los tipos ideales originales y las circunstancias nacionales de los autores; y que fueron entidades defectuosas o versiones degradadas de aquellas formas puras en relación con las cuales medían su racionalidad. En este caso la historicidad se hizo presente pero sólo como un rasgo externo, en tanto es algo que les vino a las ideas desde el contexto local, y negativo, en la medida en que estuvo involucrada en el proceso de formación de ciertos conceptos que se caracterizaron por tener un menor nivel de consistencia e integración que sus referentes europeos (Palti, 2008:32).

Por otro lado, estos historiadores impulsaron una concepción teleológica, tanto de carácter histórico como ético, de la historia intelectual de la región. Los "modelos" que forman el esquema que asumieron para articular sus obras fueron ubicados en una secuencia evolutiva: una de las alternativas quedó asociada con el pasado y fue connotada negativamente mientras que la otra se vinculó con el futuro y fue valorada positivamente. De este modo, los historiadores pasaron a considerar que necesariamente una opción, la asociada con el tiempo pasado, tendería a languidecer y la otra, vinculada con el futuro, propendería a consolidarse. Este proceso no sólo fue considerado como inevitable por estos científicos sociales sino que también fue evaluado como un decurso deseable (Palti, 2007:48 - 51; Palti, 2008:33).

En un tercer momento, empezaron a aparecer una serie de estudios que se propusieron criticar los supuestos alrededor de los que se había articulado, en particular, el esquema de modelos y desviaciones y, en general, la historia de las ideas. Los principales exponentes de tal empresa fueron el crítico literario austriaco - brasilero Roberto Schwarz y los historiadores revisionistas Charles Hale y Fracoi - Xavier Guerra ${ }^{13}$ (Palti, 2007: 27 - 39, 44 - 51; Polgovsky Ezcurra, 2010:s/d).

${ }^{13} \mathrm{Si}$ bien un análisis exhaustive de dicha bibliografía excede los límites y los propósitos del presente trabajo resulta adecuado señalar algunas de las obras de tales autores a las que se está haciendo referencia: Guerra, F. X. (1993). Modernidad e independencias. Ensayos sobre las representaciones hispánicas. MAPFRE/FCE: México; Guerra, F. X. y Lemperiere A. (1998). Los espacios públicos en Iberoamérica. Ambiguedades y problemas. Siglos XVIII - XIX. FCE: México; Hale, C. (1968). Mexican liberalism in the age of Mora, 1821 - 1853. New Haven y Londres: Yale University Press; Schwarz, R. (2000). As idéias fora do lugar. En Schwarz, R. Ao vencedor as 
Palti sostiene que tales obras tienen dos rasgos en común. Por un lado, el historiador argentino reconoce que dichos trabajos implicaron un significativo avance en la disciplina en la medida en que lograron desestabilizar ciertos axiomas en torno a los cuales se había organizado la historia de las ideas. Por otro lado, Palti también sostiene que los citados estudios, a pesar de la intención que los guiaba, no lograron trascender la perspectiva metodológica que se habían propuesto superar en la medida en que asumieron sus supuestos y reprodujeron, por ende, sus limitaciones: específicamente, en relación con el objetivo del presente trabajo, resulta necesario indicar que tales obras continuaron articulándose en torno a alterativas antagónicas (Palti, 2007:27 - 39. 47 - 51; Palti, 2005:23 - 32; Palti, 2005:82) ${ }^{14}$.

A partir de lo expuesto previamente y siguiendo a Palti, resulta posible sostener que el rasgo específico de los trabajos que adoptaron el enfoque de la historia de las ideas para analizar en pensamiento político en América Latina fue, en tanto característica que comparten los estudios de las tres etapas que se distinguieron en el marco de tal perspectiva, el de estructurarse alrededor de tipos ideales antagónicos no problematizados (Palti, 2007: 49 - 51)

También sostiene el historiador argentino que no todos los científicos sociales que asumieron la perspectiva metodológica de la historia de la ideas para estudiar el pensamiento político en la región utilizaron exclusivamente un par de conceptos antitéticos sino que asociaron, formando cadenas conceptuales, los miembros de diferentes pares antagónicos que consideran necesariamente vinculados entre sí (Palti, 2007:50, Palti, 2009:29 - 30). Palti indica que los historiadores que trabajaron con este enfoque metodológico, a la hora de configurar las cadenas conceptuales antagónicas que estructuraron sus trabajos, otorgaron un mismo valor a los diferentes miembros que asociaron para formarlas (Palti, 2007:50, Palti, 2009:29 - 30).

Este trabajo, por su parte, considera lo contrario, es decir, que los científicos sociales que utilizaron el enfoque metodológico de la historia de las ideas, en el momento de construir las alternativas antiéticas que rigieron sus obras, privilegiaron, en cada una de las cadenas conceptuales, un determinado miembro (antónimo del destacado en la cadena opuesta); cada uno de los términos de ese par se convirtió en un centro alrededor del que gravitaron otros conceptos (pertenecientes a otros díadas antitéticas) con los que, estos historiadores, consideraron que se encontraban necesariamente vinculados.

El presente trabajo, al realizar la aclaración precedente, no pretende promover una profunda revisión del argumento expresado por Palti sino que sólo se propone

batatas. Forma literária e processo social nos inicios do romance brasileiro (9 - 32). San Pablo: Livraria Duas Cidades;

${ }^{14}$ Cfr. Polgovsky Ezcurra, M. (2010). La historia intelectual latinoamericana en la era del giro lingüístico. Nuevo Mundo Mundos Nuevos, s/d. La autora considera que tales trabajos no pueden seguir siendo inscriptos en el marco de la historia de las ideas. La obra de Francoi - Xavier Guerra es considerada por esta científica social como la culminación de un proceso orientado al desmantelamiento del tradicional enfoque de la historia de las ideas que había comenzado con los estudios de Roberto Schwarz y continuado con los trabajos de Charles Hale. 
precisarlo. Como se verá más adelante, la especificación realizada configura una herramienta valiosa a la hora de exponer con mayor claridad la lógica dicotómica de la obra que se analizará.

\section{El carácter mitológico de la historia de las ideas latinoamericana}

En el presente apartado se buscará, articulando lo expuesto en las secciones previas, reconstruir el razonamiento que permite sostener que los resultados obtenidos por los trabajos que adoptaron el enfoque metodológico de la historia de las ideas latinoamericana pueden caracterizarse, siguiendo a Skinner, como mitológicos más que como históricos.

\section{La historia de las ideas en la región: más mitológica que histórica}

Los historiadores que asumieron el enfoque metodológico que caracterizó, según Palti, a la historia de las ideas latinoamericanas, en cualquiera de las tres etapas de su desarrollo, estructuraron sus trabajos alrededor cadenas conceptuales antagónicas consideradas completamente racionales, plenamente consistentes y lógicamente integradas (Palti, 2007: 49 - 51). Tal como se indicara, estos científicos sociales no sólo se preocuparon por ubicar a los diferentes autores que estudiaron en el marco de tales opciones dicotómicas sino que convirtieron tales alternativas antitéticas en los temas obligatorios sobre los que esperaron que todo teórico de la región hubiera hecho algún aporte.

Se considera legítimo argumentar de esta manera en tanto la perspectiva metodológica, cuya especificidad fue analizada en la sección anterior, comparte, en la medida en que resulta una manifestación regional de una tendencia metodológica de más amplio alcance, los supuestos que orientan las investigaciones de aquellos científicos sociales que asumen el tradicional método de la historia de las ideas (Palti, 2005; Palti. 2007; Palti, 2008; Palti, 2009).

El esfuerzo de tales politólogos se concentró, de este modo, en estudiar lo que los diferentes teóricos dijeron sobre la corriente antiética con la que los vincularon. Debe destacarse que no todos los científicos sociales comprendieron a los textos de los autores latinoamericanos como objetos completamente autosuficientes. Esto no implicó, en tanto los supuestos sobre los que se sostiene el enfoque metodológico con el que trabajaron se lo impidió, que dejaran de concebir la relación entre texto y contexto en términos de una inflexible desunión ni que pudieran entender a los trabajos analizados como algo más que un conjunto de ideas (Palti, 2009:16).

Los historiadores, al acercarse a los textos del pasado bajo la influencia de dicha perspectiva metodológica, concibieron estudios predominantemente mitológicos. A continuación se intentará proponer cómo se considera que se desplegó cada una de las mitologías indicadas en el marco de estas obras que transformaron en 
problemas perennes a las diferentes alternativas antagónicas alrededor de las que se organizaron.

\section{Mitología de las doctrinas}

Como se ha señalado, los historiadores asumen que las obras de todos los autores podrán ser clasificadas en el marco del escenario intelectual que construyeron articulando, a priori, dos cadenas conceptuales antitéticas ${ }^{15}$. Al hacerlo, trabajan con la expectativa de hallar que todos los teóricos que se encuentran analizando han enunciado doctrinas sobre los diferentes términos que configuran la cadena conceptual en el marco de la cual fueron adscriptos. Acercándose a los textos del teórico en cuestión bajo la influencia de dicho paradigma es posible que "descubran" que tal escritor haya realizado aportes que no tuvo la intención de realizar.

La mitología de las doctrinas asume dos manifestaciones. En primer lugar, es posible que el historiador, al trabajar con dicha expectativa, convierta ciertas observaciones circunstanciales y dispersas de un determinado autor en su doctrina sobre alguno de los conceptos que configuran la alternativa antitética con la que fue asociado.

Este primer modo en que se expresa este tipo de mitologías asume, a su vez, dos vías de exteriorización. Por un lado, es posible que el historiador, a partir de cierta similitud terminológica entre los enunciados del autor y los conceptos - aquellos que configuran la cadena conceptual con la que lo vincula - a los que espera que realice aportes, "descubra" que un determinado teórico realizó una contribución a un determinado tema al que, en principio, no pudo haber tenido la intención de aportar.

Por otro lado, es probable que el historiador, al estructurar su trabajo a partir de alternativas dicotómicas definidas a priori, se proponga rastrear la trayectoria de dichas alternativas a lo largo de un determinado período histórico. Los tipos ideales adquieren el carácter de entidades orgánicas cuyos ciclos vitales son homologables a los de ciertos animales; de este modo, también se descarta el rol de los agentes en dicho proceso.

Al proceder de tal manera, el historiador puede incurrir en dos tipos de absurdos históricos. Por un lado, los científicos sociales que asumen este modo de trabajar pueden embarcarse en interminables debates sobre el momento en que surgió una determinada cadena conceptual o el período a partir del cual asumió su forma más acabada.

Por otro lado, los historiadores que se proponen analizar el itinerario de las cadenas conceptuales que estructuran su trabajo pueden sentirse inclinados, al analizar la obra de determinado autor, a hablar de "anticipaciones" y valorarlas en

15 Debe recordarse que las alternativas/cadenas/tipos ideales/corrientes/opciones antagónicos/antitéticos/antagónicos son consideradas como no problematizadas, lógicamente integradas, absolutamente autoconsistentes y/o perfectamente racionales; no se agregarán estas características cada vez que se repitan las citadas expresiones para agilizar la lectura, 
función de su clarividencia. Si el historiador considera que una determinada alternativa dicotómica sólo adquirió verdadera entidad en determinado momento y también estima que un autor perteneciente a una época previa realizó enunciados que pueden ser caracterizados como anticipaciones de aquella cadena entonces los considerará valiosos en función de su capacidad para adelantarse a su época.

En segundo lugar, el científico social puede criticar, en función de la expectativa con la que trabaja, al autor que se encuentra analizando toda vez que éste haya omitido claramente realizar un aporte sobre alguno de los conceptos que configuran la corriente antitética con la que lo vinculó. Este segundo modo de exteriorización de la mitología de las doctrinas también se manifiesta de diversos modos. Entre éstos se destaca aquel en que el historiador puede atribuirle a un autor, extrapolando enunciados que haya realizado de un tema a otro, una doctrina sobre un determinado concepto, uno que forme parte de la cadena conceptual con la que lo asoció, que irresponsablemente omitió enunciar.

\section{Mitología de la coherencia}

Los historiadores articulan sus obras alrededor de dos cadenas conceptuales antitéticas y vinculan a los teóricos que analizan con alguna de estas alternativas dicotómicas. También trabajan con la expectativa de encontrar, en los textos de los autores que analizan, contribuciones a las corrientes antitéticas con las que los asociaron. Así, los científicos sociales pueden sentirse inclinados a encontrar que todos los enunciados realizados por los teóricos que estudian son, por un lado, coherentes con los conceptos que definen las alternativas con las que fueron vinculados y, por otro lado, aportes sistemáticos a dichas cadenas conceptuales. Tomar los textos bajo el influjo de este paradigma hará que resulte sumamente fácil para un historiador imponerle a la obra de un determinado escritor que se encuentre analizando una coherencia y un carácter sistemático, siempre en relación con la corriente antitética con la que lo vinculó, sin siquiera preguntarse si era la intención del autor conferírsela.

Los historiadores, luego de haber "descubierto" que los enunciados de un autor configuran contribuciones coherentes y sistemáticas a la cadena conceptual con la que lo vincularon, pueden seguir dos estrategias con el objetivo de resguardar este "hallazgo". Por un lado, los científicos sociales pueden sentirse inclinados a ignorar declaraciones que haya hecho el teórico en relación con una determinada obra o bien a desestimar trabajos enteros de dicho escritor que amenacen tanto la coherencia como la sistematicidad "encontradas" en la obra de dicho autor.

Por otro lado, los científicos sociales, también con el objetivo de salvar la coherencia y la sistematicidad "descubierta" en la obra de un determinado autor en relación con la corriente antitética con la que había sido asociado, pueden estar dispuestos a considerar a todas las contradicciones, en tanto enunciados que amenacen la imagen que se construyó de tal escritor, que puedan surgir en términos de "contradicciones aparentes". Los historiadores conjuran el carácter conminatorio de dichas expresiones reinterpretándolas de tal modo que puedan 
ser ubicadas en el marco de la cadena conceptual con la que se había vinculado al teórico en cuestión.

Finalmente, resulta necesario indicar que la mitología que se está describiendo también se manifiesta con una lógica inversa. Los científicos sociales pueden criticar a los teóricos que estudian en tanto no les resulta posible, como consecuencia de que estos autores buscaron responder diferentes interrogantes de diversas maneras, descubrir que sus trabajos son contribuciones coherentes y sistemáticas a las cadenas conceptuales con las que, en cada caso, los vincularon.

\section{Mitología de la prolepsis}

Los historiadores, tal como se ha señalado, estructuran sus obras alrededor de dos cadenas conceptuales antagónicas. También asumen que todos los autores que analizan pueden ser clasificados en el marco de tales alternativas y que deben, en función del casillero con el que fueron asociados, realizar una contribución al mismo. Los científicos sociales, al trabajar con dichos supuestos, otorgan significado a los diferentes trabajos que analizan en tanto que los consideran aportes a la corriente antagónica con la que vincularon al autor de los mismos.

Esta estrategia implica, por un lado, que la obra adquiera el significado que el historiador le otorga, en la medida en que la considera una contribución a la cadena conceptual con la que asoció al teórico que la escribió; y, por otro lado, que no se tenga en cuenta el que tenía para el autor, es decir, que no se busque investigar lo que dicho agente estaba haciendo al escribir el trabajo analizado.

Estos científicos sociales explican las obras que analizan de una manera teleológica en tanto los textos analizados adquieren significado en un momento ulterior y en relación con el propósito que estos historiadores persiguen. No existe, de este modo, una genuina preocupación, a la hora de dotar una obra de significado, por reinsertarla en el marco de su contexto intelectual de emergencia ni por identificar las intenciones del autor, es decir, la naturaleza de la intervención que implicó la escritura de dicha obra.

\section{Mitología del localismo}

Los científicos sociales organizan sus estudios alrededor de dos cadenas conceptuales antitéticas. Los historiadores consideran, en relación con ello, que los autores analizados pueden ser clasificados en el marco de dichas alternativas y también que cada uno de los teóricos estudiados debe realizar un aporte a la corriente antagónica con la que fue asociado. Estos politólogos asumen, en mayor medida de un modo inconsciente, que las corrientes antitéticas con las que organizan sus trabajos, en tanto criterios de clasificación y discriminación que adquieren entidad en un contexto temporal posterior y cultural diferente al de los teóricos que analizan, son las mismas que tenían en cuenta los autores del pasado en el momento de concebir sus obras. 
Al trabajar de este modo, lo historiadores pueden cometer dos grandes errores. En primer lugar, el científico social puede confundir la referencia de un determinado texto. El historiador, toda vez que encasille a un determinado autor dentro de una de las corrientes que definió para organizar su trabajo, estará inclinado a "descubrir" similitudes entre algunos enunciados realizados por éste y otros expresados por autores que, en el pasado, pertenecieron a la misma corriente; así correrá el riesgo de trazar una línea de "influencias" en los trabajos de los intelectuales que, en diferentes generaciones, formaron parte de alguna de las cadenas conceptuales que propone para su trabajo. El científico social no se preocupa por determinar si el autor analizado tuvo la intención, al escribir una determinada obra, de referirse a los argumentos de los autores que lo antecedieron en el marco de la misma cadena conceptual.

En segundo lugar, el historiador puede confundir el sentido de un determinado texto. El científico social vincula a los autores que estudia con alguna de las cadenas conceptuales que organizan su trabajo. Al hacerlo, estará inclinado a "descubir" cierta familiaridad entre los argumentos expresados por el autor que estudia y los diferentes términos que articulan la corriente a la que lo asoció; de este modo, es muy probable que utilice los diferentes conceptos que configuran la corriente a la que adscribió el teórico analizado como paradigmas para describir sus enunciados. En este caso, tampoco se pregunta el historiador si el teórico que se encuentra estudiando tuvo la intención de expresar sus argumentos en los términos del paradigma que está utilizando para describirlos.

\section{Una crítica a la historia de las ideas políticas argentinas: análisis de La tradición republicana de Natalio Botana}

En el presente apartado se analizará La tradición republicana de Natalio Botana partiendo de la propuesta teórico - metodológica desplegada en las secciones anteriores. En tal sentido, se tratará de establecer si dicho trabajo asumió el método de la historia de las ideas de América Latina y, en relación con ello, alcanzó, en términos de Skinner, resultados con un carácter más mitológico que histórico. La consecución de tal propósito implicará la realización de una triple tarea. En primer lugar, se intentará establecer si el autor articuló su trabajo alrededor de cadenas conceptuales dicotómicas y además si trabajó esperando que los teóricos que analizó hubieran realizado valiosos aportes a dichas opciones. En segundo lugar, se buscará, si se completa el momento previo, señalar el lugar que Botana le otorgó a Alberdi en el marco de las corrientes antitéticas que construyó para organizar su trabajo; dicha operación permitirá definir la contribución que el publicista tucumano realizó, según Botana, a la alternativa con la que fue vinculado. Por último, se tratará, en la medida en que se hayan conseguido concluir las dos tareas anteriores, la manera en que se manifestaron en la citada obra las diferentes mitologías reseñadas; la atención que 
se prestará a cada una de las mitologías estará relacionada con la intensidad con la que se hayan manifestado en el estudio de Botana.

\section{La lógica binaria y los "temas obligatorios"}

Natalio Botana se propone estudiar el origen y desarrollo, durante el siglo XIX, de la tradición republicana argentina, es decir, del principio de legitimidad erigido para ocupar el espacio que había dejado aquel que la ruptura del pacto colonial había arrastrado consigo (Botana, 2005: 16). Esta tarea implica, para el politólogo, tener en cuenta, en primer lugar, la historia política argentina entre la Revolución de Mayo y la federalización de la ciudad de Buenos Aires, en segundo lugar, el horizonte de ideas políticas construido en Europa Occidental entre mediados del siglo XVIII y finales del siglo XIX y, en tercer lugar, las obras de Alberdi y Sarmiento (Botana, 2005:16).

Son los textos de estos publicistas argentinos a los que recurre Botana para alcanzar el objetivo que se propuso porque considera que son ellos, principalmente, los que forjaron el principio de legitimidad republicano; lo hicieron contrastando las ideas políticas dominantes del escenario intelectual europeo de su época con las circunstancias políticas locales (Botana, 2005:16).

La historia de esta legitimidad de reemplazo sólo puede trazarse, según Botana, si se tiene en cuenta que los citados publicistas articularon sus reflexiones en torno a la misma a lo largo de un período que puede ser dividido en tres etapas. En primer lugar, lo que Botana denomina, siguiendo a Tocqueville, el "punto de partida", es decir, las reflexiones juveniles de Alberdi y Sarmiento que se plasmaron en sus proyectos de nación (Botana, 2005:20).

En segundo lugar, el período del "orden político"; los pensadores seleccionados, ya maduros, vuelven a pensar los proyectos, concentrados en fijar un entramado institucional adecuado para que pudieran ser llevados a cabo, que habían concebido a la luz de su implementación parcial en una realidad que los incorpora (muchas veces desviándolos) y que también los rechaza. Por último, en tercer lugar, el momento del "porvenir del gobierno republicano en la Argentina", es decir, las reflexiones de ambos publicistas, en la última etapa de sus vidas, acerca de las consecuencias buscadas y también las no deseadas de la implementación de aquellos proyectos que habían comenzado a delinear durante su juventud (Botana, 2005: 20).

Una vez establecido el marco general del trabajo, resulta posible indicar que la obra de Botana se encuentra atravesada por dos dicotomías. La primera está determinada por el antagonismo que se da entre el principio de legitimidad republicano y el monárquico; y, la segunda, por la oposición que se establece entre la república de la virtud/ciudadanos y la república del interés/habitantes. El esfuerzo del politólogo no se concentra en el primer nivel de análisis sino en el segundo; ésto se debe a que el propósito de su trabajo, tal como se ha visto, consiste en analizar la configuración de la tradición republicana en la argentina. 
Desde las primeras hojas de su trabajo, el politólogo traza la dicotomía que determinará la anatomía de su obra. Por un lado, la república de la virtud articulada alrededor de la asociación de conceptos tales como ciudadanía libertad de los antiguos - libertad política - primacía de lo público - comunidad y, por otro lado, la república del interés configurada a partir de la asociación de términos tales como habitante - libertad de los modernos - libertad civil - primacía de lo privado - individuo. Así queda establecido en el prólogo:

“ ¿Sonará redundante aseverar - tanto la teoría política ha insistido al respecto que la república entraña un tenso diálogo entre libertad e igualdad? Esta mirada abarca la autonomía individual protegida por resistentes garantías e ilumina una comunidad política constituida por ciudadanos iguales. Propone un periplo que arranca con una meditación acerca del sentido antiguo de la virtud del ciudadano, sobre la cual, se aducía, debía descansar la legitimidad de la república, y concluye viendo cómo se levanta un criterio alternativo fundado en el interés particular del habitante. La polaridad entre virtud e interés, o - así las llamaré más adelante entre una república de ciudadanos y una república de habitantes, atraviesa el espacio y los temas que aquí se tratan" (Botana, 2005:20)

Tales polos antagónicos se convierten, en la medida en que configuran las vertientes de la tradición republicana que el autor se propone reconstruir, en los temas obligatorios sobre los que Botana espera que los publicistas analizados realicen significativos aportes; en particular, Alberdi será el que vitalice la república del interés y Sarmiento el que moldee la de república de la virtud.

El trabajo acepta que la reconstrucción del horizonte intelectual que realiza con singular erudición Botana no se limita a estos dos modelos antitéticos. En relación con esto resulta necesario hacer algunas aclaraciones relativas al resto de los aportes teóricos que completan el marco europeo de ideas políticas. En primer lugar, es preciso indicar que se presentan teniendo como referencia las dos corrientes de la tradición republicana que se busca reconstruir. En segundo lugar, resulta adecuado señalar que, a pesar de que se tienen en cuenta tales alternativas antitéticas para organizar la exposición, no se establece un vínculo necesario entre dichos corrientes teóricas y los modelos dicotómicos alrededor de los que se articula la obra.

En tercer lugar, es pertinente destacar que, si bien no se establecen relaciones necesarias entre dichos aportes teóricos y las opciones dicotómicas, ciertos autores o teorías son asociados más fuertemente con dichas alternativas. Por último, cabe señalar que dichas recursos teóricos, los que completan el horizonte de ideas europeas, se presentan como herramientas que sirven, según el momento y la circunstancia, para que Alberdi y Sarmiento cimienten sus posiciones en torno a una u otra de las alternativas dicotómicas prefijadas. Botana parece dejar clara su posición cuando sostiene: 
"Dos puntos extremos [república de la virtud y república del interés], pues, y una promesa de reconciliación. A medio camino he ubicado escalas: el contraste entre el bien que persigue el ciudadano virtuoso y las consecuencias imprevisibles de la acción humana; la querella que contrapone formas puras y formas mixtas de gobierno; el novedoso concepto que distingue dos tipos de participación política, directa e indirecta; el papel del pluralismo frente al nuevo fenómeno de la centralización estatal; los tropiezos del paradigma ecléctico, deseoso de pactar la paz entre principios en guerra; el arrogante ascenso de la sociedad industrial con sus profetas; la inteligencia, en fin, de una teoría democrática que, como obra del arte político, sea capaz de conjugar igualdad y libertad, virtud e interés" (Botana, 2005: $20-21$ ).

\section{La "contribución" de Alberdi}

Botana, luego de desplegar los modelos antitéticos y las herramientas teóricas disponibles para fundamentarlos, hace entrar en escena a los protagonistas principales de su obra, es decir, a los constructores de la tradición republicana. Alberdi será, tal como se señalara, el que de vida a la república del interés y Sarmiento a la república de la virtud. Este trabajo se ocupará del análisis que el politólogo argentino realiza de los textos del publicista tucumano.

Tal como se indicó previamente, Botana analiza el pensamiento de Alberdi (del mismo modo que el de Sarmiento) teniendo en cuenta tres momentos o dimensiones. En primer lugar, comienza con el "punto de partida" o reflexiones juveniles que adquirieron cuerpo en una primera formulación de su proyecto de nación. Para exponer la lectura que hace Botana sobre esta dimensión del pensamiento alberdiano resulta pertinente reconstruir la lógica de su argumentación.

Botana sostiene que Alberdi parte de asumir que toda ley o gobierno de una determinada nación debe estar en consonancia con sus costumbres. Continúa estableciendo su rechazo a las costumbres imperantes en su país y, consecuentemente, la necesidad de reformarlas; sólo entonces sería posible comenzar a pensar en un nuevo horizonte político. El Alberdi del Fragmento Preliminar, según Botana, considera necesario desentrañar la naturaleza de esa nación para postular una constitución adecuada a ella; reconciliando, de ese modo, la razón universal con las circunstancias particulares y ubicando, de esa manera, a la nación en sobre los rieles del progreso civilizatorio y de la democracia (Botana, 2005:286 - 289).

Tan sólo dos años más tarde de la publicación del Fragmento Preliminar, Alberdi, según Botana, mantuvo su rechazo a las costumbres imperantes en su época pero abandonó el gradualismo (en relación con el mecanismo para modificarlas) que su adhesión al historicismo le había impuesto. En aquellos años, sostiene Botana, comenzó a intuir, en el marco de un voluntarismo legislativo que lo alejaba radicalmente de su postura inicial, que era necesario crear las costumbres adecuadas para derogar la herencia colonial (Botana, 2005:290). Testimonio de esta modificación de su pensamiento es su obra La Acción de Europa en la 
América; en ella esbozó por primera vez la teoría del trasplante de costumbres civilizadas e industriales a través de la inmigración de europeos (prioritariamente, anglosajones). (Botana, 2005:293).

La reforma de la sociedad no se completaba con el mero hecho de la inmigración sino que era necesario garantizar el máximo de libertad civil a cada uno de los extranjeros portadores de costumbres civilizadas e industriales para que operase, espontáneamente, el reemplazo de una cultura típica de la Europa colonial, humanista y letrada por otra característica de la Europa moderna, comercial e industrial. Esta conclusión se plasma claramente, según Botana, tanto en las Bases como en Sistema Económico y Rentístico, obra, esta última, en la que, según el politólogo, termina de reflejarse la asunción de una perspectiva iluminista (Botana, 2005: 304). Sólo hay entre estos dos trabajos de Alberdi una diferencia de énfasis en relación con el vínculo virtuoso existente entre libertad civil y costumbres civilizadas:

"Entremezcladas en mil pasajes, parece difícil discernir con exactitud la primacía de una u otra visión. En todo caso, si hubiera que reducir el matiz a esquema, es posible observar a las Bases...como un elogio a la costumbre creadora de libertad y al Sistema...como un elogio a la libertad creadora de costumbres" (Botana, 2005:299).

Así se llega a una imagen más clara del punto de partida que, según Botana, asume Alberdi. Se trata de modificar la sociedad pero no aceptando un cambio gradual de las costumbres, tal como lo hacía en su etapa romántica, sino promoviendo su radical modificación, ya en el marco de una propuesta iluminista, a través de una masiva inmigración portadora de hábitos civilizados e industriales y otorgando a cada individuo extranjero el más amplio abanico de libertades civiles. Sólo entonces podría comenzar a pensarse en una política auténticamente diferente.

La segunda dimensión del trabajo de Alberdi que analiza Botana es "el orden político", es decir, el conjunto de reflexiones que realizó el publicista tucumano durante su madurez orientadas a dilucidar el entramado institucional que daría marco al proyecto que había concebido durante la etapa anterior.

Para exponer la lectura que Botana hace de esta dimensión de Alberdi se debe recordar que, según el politólogo, el publicista tucumano consideraba que una mejora en la esfera política sólo podía alcanzarse si, previamente, operaba un perfeccionamiento en el plano social. Una auténtica y completa legitimidad republicana no sería posible hasta que no se generase un terreno de sólidas y adecuadas costumbres sobre el que fuera posible erigirla. El proyecto concebido en la etapa previa estaba orientado en su totalidad a promover una modificación de la sociedad. El interrogante se planteaba en relación con el orden político adecuado para la transición entre un tipo social y otro; responderlo implicaba tener en cuenta que el diseño del entramado institucional debería, por un lado, promover 
ese radical cambio en el plano de las costumbres y, por otro lado, corresponder con el tipo de hábitos imperantes en la sociedad que le daría vida.

Botana divide las reflexiones de Alberdi en torno a esta temática en dos momentos. La primera etapa, abierta con el derrocamiento de Rosas y cerrada con la secesión de Buenos Aires, se caracteriza por la propuesta de un gobierno mixto construida con herramientas provistas por el pensamiento doctrinario. El orden político postulado configura una solución de compromiso entre dos legitimidades incompletas, entre un principio tradicional y otro moderno; transacción que se refleja en diferentes dimensiones de la propuesta alberdiana (Botana, 2005:343). En primer lugar, se constata en la relación que se establece entre la libertad política y la civil. Se garantizaba el más amplio abanico de libertades civiles para todos los habitantes pero se circunscribía rígidamente la participación política a un número reducido de ciudadanos (Botana, 2005:333). Los votos, las armas y la educación obligatoria debían evitarse en tanto interferían con la acción espontánea de las costumbres, llave maestra de la redención social (Botana, 2005:335 - 336).

En segundo lugar, el compromiso se reflejaba también en la forma de gobierno. Se instituía un orden republicano pero se postulaba, a la vez, la necesidad de un poder ejecutivo fuerte (Botana, 2005:339). En tercer lugar, se observa con claridad en la forma de estado. Se establece una federación mixta que respeta la existencia de un gobierno nacional y también reconoce las autonomías provinciales; la relación entre la nación y las provincias quedaba subordinada a los preceptos constitucionales (Botana, 2005:346). Por último, también se observa esta lógica transaccional en el plano religioso. Se decreta la libertad de cultos pero se privilegia el rol del catolicismo en la educación (Botana, 2005:347).

La segunda etapa de las reflexiones de Alberdi en torno al orden político está enmarcada en el resurgimiento de la guerra civil entre Buenos Aires y el Interior. El retorno del conflicto entre los viejos contendientes implicaba el fracaso de su propuesta inicial y la imposibilidad de la aplicación del proyecto concebido durante el punto de partida. Era necesario revisar los argumentos doctrinarios y mixtos del primer momento para estar en condiciones de realizar una nueva propuesta que no sólo se adecuara a la sociedad de transición y promoviera una profunda reforma social sino que también permitiera, principal y previamente, el logro de la paz (Botana, 2005:380).

En esta etapa, la propuesta política alberdiana, orientada al establecimiento de la paz como precondición para la aplicación de su proyecto de redención social, implicó, por un lado, una integración política deliberada y violenta de la frontera hacia adentro y, por otro lado, una integración económica - religiosa de carácter espontáneo de la frontera hacia afuera (Botana, 2005:380).

En el orden interno, la integración sólo se lograría estableciendo una monarquía aristocrática fuertemente centralizada capaz de monopolizar, finalmente, el poder y la fuerza (Botana, 2005:380). En el marco de esta dimensión interna de la integración política es que pueden entenderse, según Botana, las reflexiones de Alberdi en torno a la imperiosa necesidad de federalizar la Ciudad de Buenos 
Aires (Botana, 2005:388). En el orden internacional, el país debía adecuarse a la lógica natural y espontánea de integración que gobernaba al mundo abrazando los pilares sobre los que aquella descansaba, es decir, el comercio y el cristianismo (Botana, 2005:388).

La tercera dimensión o etapa del pensamiento de Alberdi en torno a la tradición republicana es la que recoge sus reflexiones sobre el "porvenir del gobierno republicano en la Argentina", es decir, el conjunto de observaciones realizadas por este publicista, en su vejez, referidas a la relación entre sus propuestas y el escenario político nacional de fin del siglo XIX.

Alberdi, según Botana, mantiene en su vejez los grandes lineamientos intelectuales trazados durante su juventud y profundizados en los años de madurez. El "punto de partida" de Alberdi era la convicción de que resultaba necesario modificar radicalmente las costumbres locales promoviendo la inmigración de la Europa moderna y permitiendo que su espontáneo desenvolvimiento redimiera la corrupta sociedad que habitaba este país. Estas viejas convicciones, sostiene Botana, vuelven a manifestarse con la misma intensidad en la pluma de un sexagenario Alberdi. En La vida y los trabajos industriales de William Wheelwright en la América del Sud Alberdi hace una apología de la labor civilizatoria de las costumbres industriales sajonas encarnadas en el trabajo e iniciativas de su cliente William Wheelwright; la teoría del transplante de costumbres, piedra angular de su proyecto, se reedita en formato biográfico (Botana, 2005:406 - 407).

El "orden político" debía configurar el marco que posibilitara y promoviera la modificación de la sociedad. Un estado nacional fuerte, centralizado y capaz incorporar a la ciudad de Buenos Aires al conjunto de la nación era el camino prescripto por Alberdi. Sólo entonces habría quedado configurado el molde institucional dentro del que fuera posible verter su proyecto de regeneración social. La República Argentina consolidada en 1880 con la ciudad de Buenos Aires por capital y La omnipotencia del Estado es la negación de la libertad individual son las obras en las que, según la interpretación de Botana, reaparecen las reflexiones de Alberdi sobre la organización política; en particular, se manifiestan en dos sentidos.

Son las obras en las que vuelve a manifestarse, según la interpretación de Botana, la lógica que subyace, conjunto de las reflexiones de Alberdi en torno a la organización política; en particular, encarna en dos temas propios de la coyuntura política argentina de finales del siglo XIX.

En primer lugar, en los pensamientos del publicista tucumano referidos a la organización del estado nacional; en este sentido, Alberdi celebra la derrota de Buenos Aires y su definitiva incorporación a la nación. La "reducción a la unidad"16

\footnotetext{
16 Nos referimos a la fórmula utilizada por Botana en El orden Conservador. Allí el politólogo sostiene: "En trabajos anteriores he procurado analizar, desde el punto de vista teórico, el proceso que da origen a una unidad política y lo he denominado, siguiendo a $\mathrm{R}$. Braun, reducción a la unidad. De un modo otro, por la vía de la coacción o por el camino del acuerdo, un determinado sector de poder, de los múltiples que actúan en un hipotético espacio territorial, adquiere el control
} 
conjuraba los fantasmas de ilegitimidad que habían acechado a los múltiples intentos erigir un estado nacional que tuvieron lugar desde la ruptura del pacto colonial (Botana, 2005:418).

En segundo lugar, en las reflexiones de Alberdi relacionadas con la manifiesta ilegitimidad del régimen político. No se ajustaba la práctica a las prescripciones constitucionales desde el momento en que los gobernantes invertían la lógica representativa eligiéndose a sí mismos ${ }^{17}$ (Botana, 2005:421). La corrupción de la república no significaba otra cosa que la ineptitud de la sociedad, todavía incapaz de gobernarse a sí misma (Botana, 2005:421).

La conclusión a la que arriba publicista tucumano, muñido en aquel momento de nuevas herramientas teóricas, cierra el círculo que refleja la continuidad que, según la lectura de Botana, caracteriza al pensamiento alberdiano. No habría una auténtica legitimidad republicana hasta que no existiera una sociedad que estuviera a la altura de ese desafío político. Las costumbres debían ser reformadas, sólo el masivo advenimiento de inmigrantes anglosajones a los que, por un lado, se les garantizara el más amplio abanico de libertades civiles para que pudieran perseguir sus propios intereses y, por otro lado, no se les impusieran obligaciones políticas sería el camino apropiado para regenerar a la sociedad; sólo entonces sería el tiempo de la República verdadera (Botana, 2005:427). Queda reconstruida la lectura que Botana realizó del pensamiento político de Alberdi, el rasgo más saliente del mismo resulta ser la continuidad en torno a una concepción de república, la del interés.

\section{Las mitologías}

Una crítica del trabajo de Botana en el sentido en que este trabajo propone debe estar precedida por dos aclaraciones. En primer lugar, debe destacarse que el estudio de este politólogo configura un valioso aporte a la disciplina en tanto es un trabajo sumamente sofisticado y erudito. En segundo lugar, también debe señalarse que, en ciertos pasajes, se puede verificar que Botana postula algunas hipótesis en relación con lo que Alberdi hacía al escribir ciertos textos. Este intento por recuperar la historicidad de algunas obras del publicista tucumano, en el sentido del enfoque metodológico "skinnereano" asumido por el presente trabajo, no satisface, por diferentes razones, los requisitos metodológicos que la perspectiva a la que se adhiere demanda.

Por un lado, en tanto se parte de encasillar a Alberdi en la cadena que reconoce como significante privilegiado a la República del interés, todas las hipótesis relativas al carácter performativo de alguna obra de Alberdi solo adquieren sentido en ese marco. Si Alberdi apoyó determinado argumento o lo invirtió adquiere

imperativo sobre el resto y lo reduce a ser parte de una unidad más amplia. Este sector es, por definición, supremo; no reconoce, en términos formales, una instancia superior; constituye el centro con respecto al cual se subordina el resto de los sectores y recibe el nombre de poder político (o como se leerá más adelante, poder central)" (Botana, 1998:26 - 27).

${ }_{17}$ Es un razonamiento que recuerda el sostenido por Botana en el tercer capítulo de El orden conservador en el que sostiene la tesis de la hegemonía gubernamental (Botana, 1998: 65 - 82). 
relevancia por el sólo hecho que lo hizo para construir esta corriente de la tradición republicana nacional.

Por otro lado, la reconstrucción del horizonte de ideas políticas, de por sí completo, se presenta más como una caja de herramientas a la que pueden acudir tanto Alberdi y Sarmiento para construir las corrientes en las que, respectivamente, fueron encasillados que como un contexto intelectual en el marco del cual han intervenido, en diferentes momento, con disímiles intenciones. Tampoco se presta atención, en esa reconstrucción, a los trabajos realizados por los pensadores, intelectuales y teóricos nacionales durante el período que preocupa al trabajo de Botana. Recuperar el significado de algún texto de Alberdi y Sarmiento no puede realizarse sólo atendiendo a lo que se pensaba en Europa occidental sino que también implicaría tener en cuenta las obras nacionales que buscaban brindar respuestas a los mismos problemas que incitaban la reflexión de dichos publicistas.

Por último, es necesario señalar que en los casos en los que se busca identificar la naturaleza de alguna intervención de Alberdi (estar a favor, en contra, apoyar, de algún argumento) no se lo hace atendiendo al conjunto del contexto intelectual sino que se lo deriva de un diálogo impuesto, en tanto no se manifiesta una preocupación por desentrañar si era o no la intención del autor establecerlo, con ciertos autores particulares.

Realizadas las aclaraciones, puede proseguirse postulando el carácter mitológico de la obra de Botana aquí analizada. Botana estructura su trabajo alrededor de las dos corrientes de la tradición republicana que busca reconstruir, la república de los habitantes y la de los ciudadanos. Dichas alternativas asumen el carácter de temas obligatorios sobre los que el politólogo espera que los autores que analiza realicen significativas contribuciones. Al trabajar con dichos supuestos, Botana se preocupa por analizar lo que ambos publicistas dijeron sobre cada una de las corrientes con las que los vinculó. La obra, aunque erudita y compleja, tiene, por las razones señaladas, un carácter predominantemente mitológico.

Toda la lectura que el politólogo argentino hace de los textos de Alberdi que analiza se encuentra determinada por la alternativa dicotómica con la que lo vincula. Tal como se indicó, Botana considera que Alberdi se ubica, en el marco de la lógica dicotómica que atraviesa su trabajo, dentro de la alternativa de la república del interés, corriente de la tradición republicana a la que dio vida con su pluma. El supuesto queda, tal como se vio previamente, establecido desde el prólogo de la obra analizada.

La mitología de las doctrinas se manifiesta en la obra de este politólogo. Botana, al ubicar a Alberdi en uno de los casilleros, se encuentra inclinado a interpretar sus obras como aportes a cada uno de los miembros de la cadena conceptual con la que lo asoció. No se trata de que el politólogo no analizara la minuciosamente los enunciados de Alberdi sino que los dotara de significado en tanto intervenciones orientadas a dar vida al tipo ideal definido. Todas sus obras, desde los escritos de la juventud hasta los textos de la vejez, son interpretadas como aportes a la 
construcción de una tradición republicana basada en la libertad negativa y el interés particular.

La mitología de coherencia se manifiesta con mucha fuerza en el trabajo de Botana. Según la lectura del politólogo, Alberdi mantiene, durante toda su obra, una rígida adscripción a la corriente de la República del interés, casillero en el que había sido ubicado por él. La erudición de su trabajo le impide "salvar" la coherencia que le había impuesto a la obra del publicista tucumano obviando algunos textos o declaraciones que pudieran amenazarla. Las contradicciones que pudieran plantear algunos textos problemáticos, en particular El Fragmento Preliminar y las Cartas Quillotanas, son consideradas "aparentes" y resueltas reubicándolas en el marco interpretativo prefijado.

El Fragmento Preliminar amenaza la sistematicidad impuesta a la obra de Alberdi en tanto incluye algunos enunciados que podrían ser interpretados como apoyos al gobierno rosista. Para comprender como Botana desarticula esta posibilidad es necesario reconstruir su razonamiento. Para el politólogo, en esta obra está contenido gran parte del punto de partida alberdiano, falta la solución radical que sólo podría postular luego de abandonar el historicismo que informa esta obra. El valor de las costumbres como determinantes del orden político, el rechazo de los hábitos existentes y la necesidad de reformarlos para alcanzar un estadio político superior de carácter republicano son elemento que ya están presentes en este texto (Botana, 2005:286 - 287).

Las reflexiones sobre Rosas sólo adquieren sentido, en la interpretación de Botana, en dicho marco. No implican un acercamiento al Gobernador de Buenos Aires sino la aplicación al caso particular de su concepción de la relación entre sociedad y política, entre costumbres y leyes. El Restaurador de Las Leyes es producto de una nación. Es una política que debe cambiarse, logro que sólo podría ser alcanzado mediante una reforma de las costumbres. En esta etapa, domina una solución gradualista impuesta por el historicismo al que todavía adhería. Así lee Botana esta obra:

“¿Qué hacer entonces? Las costumbres son soberanas y esa soberanía es mala. Este implícito homenaje a la teoría de la soberanía de Guizot tenía, para Alberdi, la virtud de legitimar al gobernador de Buenos Aires ("Rosas considerado filosóficamente no es un déspota que duerme sobre bayonetas mercenarias. Es un representante que descansa sobre la buena fe, sobre el corazón del pueblo") sin desconocer, por cierto, la prehistoria instintiva sobre la cual descansaba esa forma de gobierno. Porque, en rigor, no hay pasado digno de figurar como buena legitimidad. Condenados a peregrinar en "embrión", como un "bosquejo", desde un ayer marcado por el "dominio del instinto", los argetinos, aun inmersos en una anacrónica edad heroica, no tienen ante sí otra tarea que despojarse de esa herencia." (Botana, 2005:287)

Las Cartas Quillotanas también podrían configurar una amenaza para la coherencia que Botana impone a la obra en tanto comprende algunos enunciados 
que podrían interpretarse como reivindicaciones del caudillismo. Una vez más, debe reconstruirse el hilo del argumento que Botana propone para desarticular esta nueva amenaza. En este caso, es necesario tener en cuenta dos argumentos importantes de la interpretación que Botana hace del pensamiento de Alberdi. En primer lugar, el énfasis puesto por Alberdi en resaltar que todo régimen político debe corresponder con las costumbres de la sociedad en el marco de la cual se establece. En segundo lugar, y derivado del anterior, la propuesta, por lo menos en una primera etapa, de un orden político mixto que se fundamentara en la integración de principios políticos antagónicos, el unitario y el federal.

En este contexto, los citados enunciados no son interpretadas como una apología de la política vernácula sino como la aceptación de una realidad destinada a extinguirse con la que resultaba, para lograrlo, necesario transigir. Por un lado, la aceptación de una sociedad que sólo podría modificarse a medida que el trasplante de cultura hiciera, espontáneamente, su trabajo; el caudillo sólo dejaría de existir cuando las costumbres sobre las que descansa dejaran languidecieran. Así lo expresa Botana: "Por eso ante las disyuntiva entre civilización y barbarie Alberdi resuelve combatir el caudillismo en sus causas y apoyar la política que prevalecía en el mundo rural. El caudillo entendido como expresión política del antiguo régimen, no será erradicado hasta tanto no desaparezcan las causas que lo engendraron" (Botana, 2005:338). Más adelante, en el mismo sentido, el politólogo sostiene:"En todo caso, hasta que el trasplante produzca efectos, es preciso acatar la realidad del mundo rural como fuente y sustento del orden político" (Botana, 2005:339).

Por otro lado, vinculado con el punto anterior, la concesión que debía hacerse, en el marco de una república posible, a la vieja legitimidad. Botana lo deja claro al escribir:"Parece claro que Alberdi persigue legitimar el orden político emergente bajo la protección de criterios tradicionales. La tradición que se recupera es, ante todo, política. Es la mediación necesaria para alcanzar los fines de progreso en la sociedad" (Botana, 2005:339).

La mitología de la prolepsis también aparece con claridad en este trabajo. Como se indicó, Botana busca reconstruir las dos corrientes que configuraron la decimonónica tradición republicana de este país. Su trabajo está guiado por la adscripción de los autores elegidos a cada una de las cadenas conceptuales alrededor de las que estructura su estudio: Sarmiento queda asociado a la república de los ciudadanos y Alberdi a la república de los habitantes. A partir de ahí, toda la obra del publicista tucumano (y también la del sanjuanino) adquieren sentido en el marco del objetivo señalado. De este modo, se pone el énfasis en el significado que tienen los textos de Alberdi para Botana y, a la vez, se subestima el que podría haber tenido para el propio autor de los mismos.

La mitología del localismo se encuentra presente a lo largo de todo el trabajo. Como se ha repetido, Botana parte de asociar a Alberdi con la cadena conceptual que reconoce a la república del interés como su significante privilegiado. Articular su trabajo alrededor de las cadenas conceptuales indicadas hace que, a través del mecanismo indicado en la sección previa, Botana se sienta inclinado a homologar sus criterios de clasificación y discriminación con los que contaba Alberdi al 
escribir sus obras. Como se ha indicado, este tipo de mitología puede manifestarse de dos modos alternativos.

Exponer el primer modo de expresión de este absurdo histórico implica recordar que, tal como se señalara previamente, la reconstrucción del horizonte de ideas no se agota en la definición de los tipos ideales dicotómicos alrededor de los que articula su obra. Sólo quedan asociados necesariamente a éstos los autores que dieron vida a cada uno de los pares antitéticos, Rousseau a la República de la virtud y Adam Smith a la república del interés. Los teóricos que completan el clima intelectual de Alberdi y Sarmiento reconstruido por Botana se encuentran contingentemente vinculados con cada uno de los polos de la dicotomía que gobierna la obra. ${ }^{18}$ Éstos se despliegan frente a los autores como herramientas a las que pueden recurrir para cimentar o construir, según las necesidades que el momento imponga, las corrientes de la tradición republicana que cada uno, según Botana, encarna.

Botana no tarda en "descubrir" similitudes entre los enunciados de Smith y Rousseau, en tanto autores que quedaron vinculados necesariamente con cada una de las cadenas conceptuales antitéticas, y las obras de Alberdi y Sarmiento. De este modo, el politólogo convierte a estos teóricos europeos en dos de las "influencias" que los publicistas argentinos mantienen a lo largo de toda sus trayectorias intelectuales ${ }^{19}$. El resto de los pensadores, los que completan el horizonte de ideas políticas pero que sólo se vinculan de manera contingente con cada uno de los polos antitéticos, también son relacionados con las diferentes obras de los escritores argentinos en términos de "influencias" pero, en este caso, que no se mantienen a lo largo de todos sus trabajos; sólo se convierten en referencias cuando son utilizados por Alberdi y Sarmiento para construir las alternativas republicanas que cada uno representa. En ambos casos, no se tiene en cuenta si podía ser la intención del autor referirse, en cada uno de los enunciados que realizaba, a los autores con los que Botana los asocia en términos de "influencias".

\footnotetext{
${ }^{18}$ Sin embargo no está de más recordar que el paradigma de las dos tradiciones republicanas también gobierna la reconstrucción del horizonte de ideas. En ese sentido, existen autores que quedan más cerca de una u otra propuesta. Cuanto más vinculados se encuentre algún teórico, desde la perspectiva de Botana, a alguna de las alternativas antitéticas más probable es que aparezca como una "influencia" mantenida durante toda la obra de Alberdi y Sarmiento.

${ }^{19}$ En el caso de Alberdi, la historia de su obra es, según la lectura de Botana, el relato de la gradual transición desde el historicismo que da vida al Fragmento Preliminar hasta la adopción del economicismo individualista liberal de Adam Smith; cuya primera manifestación "pura" se observa, según Botana, en Sistema Económico y Rentístico (Botana, 2005: 304). El politólogo lo expresa con claridad en la conclusión: "De joven, como no podía ser de otra manera, Alberdi atravesó una circunstancia en que hacían eclosión los grandes temas de la conciencia histórica. La Argentina y América del Sur se incorporaron a la revolución, padecieron rupturas abruptas con el pasado y, arrastradas por el vértigo de una continuidad profunda, pronta a renacer e imponerse. Pero eso, el drama de la gran historia no fue más que un episodio impuesto por la necesidad. Muy pronto Alberdi se apartó con disgusto de esas imágenes que lanzaban mil destellos para recuperar y atender a una historia cotidiana - la historia del común mortal en ejercicio de su libertad civil - tal cual la pensaron Adam Smith, Ferguson y, ya entrado el siglo, Spencer." (Botana, 2005:454 - 455).
} 
También se verifica en la obra el segundo modo de manifestación de esta mitología. Al partir de asociar rígidamente a Alberdi a una de las cadenas conceptuales, Botana interpreta todos sus enunciados en función de los términos que configuran tal tipo ideal. Cualquier expresión pasa por el tamiz constituido por conceptos como "república de habitantes", "interés", "libertad negativa" o "libertad moderna". No se trata de negar que Alberdi haya tenido la intención de realizar aportes en tales sentidos sino de afirmar que resulta imposible asumir que haya sido su intención hacerlo, y en el mismo sentido, cada vez que escribió una obra a lo largo de su vida.

\section{Conclusiones}

Este artículo, tal como se señalara, se inscribe en el marco de un proyecto de investigación más ambicioso que se plantea establecer que los trabajos que se preocuparon por estudiar el pensamiento político de Juan Bautista Alberdi, al menos una cantidad relevante de los mismos, alcanzaron, al haber asumido la perspectiva metodológica que caracterizó a la historia de las ideas en América Latina, resultados que pueden ser caracterizados, siguiendo a Skinner, como predominantemente mitológicos. En relación con los objetivos que el presente artículo se propuso resulta posible concluir:

1. El carácter predominantemente mitológico de la historia de las ideas latinoamericana derivó de que los autores, por un lado, estructuraron sus obras alrededor de cadenas conceptuales antagónicas no problematizadas y, por otro lado, trabajaron esperando que los autores analizados hubieran realizado una significativa contribución (por lo menos, a alguna) de tales opciones antitéticas.

2. La tradición republicana adoptó el método de la historia de las ideas latinoamericana y, al hacerlo, se convirtió en un trabajo en el que predominó el carácter mitológico por sobre el histórico. En primer lugar, se observó que la lógica binaria se hizo presente en la obra de Botana en dos planos. Por un lado, en el conflicto entre el principio de legitimidad republicano y monárquico y, por otro lado, en la oposición entre república de la virtud y del interés; esta última antinomia, que se dio en el marco de la tradición republicana, fue la que concentró la atención del autor. También se pudo determinar que las opciones dicotómicas se convirtieron en los conceptos fundamentales sobre los que el politólogo esperó que los publicistas analizados realizaran aportes. De este modo, el autor pasó a concentrarse, particularmente, en estudiar lo que dichos autores habían dicho sobre las cadenas conceptuales con las que los asoció. En segundo lugar, se señaló el lugar en el que Botana ubicó, en el marco de su esquema binario, la obra del publicista tucumano; esto permitió identificar la contribución que, según el politólogo argentino, realizó Alberdi a la opción antagónica con la que fue 
asociado. El autor vinculó rígidamente a Alberdi con la construcción de la corriente de la tradición republicana que denomina república del interés o de los habitantes. En tercer lugar, se verificó la presencia de las cuatro mitologías en la citada obra.

3. El trabajo realizado abre el camino para profundizar la línea de investigación propuesta, por lo menos, en dos sentidos. En primer lugar, podría, tal como busca hacerlo el proyecto en el que se inscribe el presente artículo, aplicar la propuesta teórico - metodológica esbozada al análisis de otras obras que se dediquen al estudio del pensamiento político de Juan Bautista Alberdi. En segundo lugar, sería posible utilizar la citada propuesta para estudiar los trabajos que se hayan elaborado sobre las reflexiones políticas de algún otro autor del período o contemporáneo.

\section{Bibliografía}

En Altamirano, C. Para un programa de historia intelectual y otros ensayos (77 104). Buenos Aires: Siglo XXI.

Álvarez Solís, A. O. (2011). Conceptualizando América. Historia de los conceptos e ideas fuera de lugar. Nuevo Mundo Mundos Nuevos, s/d. Recuperado en: http://nuevomundo.revues.org/62459

Babaj, R. (2010). Intellectual history. s/d. Recuperado de: http://docupedia.de/zg/Intellectual_History

Blanco, J. J. (2009). Teoría de sistemas e historia de las ideas. Aportes sistémicos al debate de la historia de las ideas. Persona y Sociedad, XXIII(2), pp. 91 - 113.

Botana, N. (1998), El orden conservador, Buenos Aires: Sudamericana.

Botana, N. (2005). La tradición republicana. Alberdi, Sarmiento y las ideas políticas de su tiempo. Buenos Aires: Sudamericana. 
Di Pasquale, M. A. (2011). De la historia de las ideas a la nueva historia intelectual: Retrospectivas y perspectias. Un mapeo de la cuestión. Revista UNIVERSUM, 26(1), pp. $79-92$.

Fernandez Sebastian, J. (2002). Historia de los conceptos. Nuevas perspectivas para el estudio de los lenguajes políticos europeos. Revista de Historia Ayer, 48, $331-364$.

Gordon, P. (2012). What is intelectual history? A frankly partisan introduction to a frequently misunderstood field, s/d. Recuperado de: http://history.fas.harvard.edu/people/faculty/documents/What\%20_is_Intell_History \%20PGordon\%20Mar2012.pdf

Guerra, F. X. (1993). Modernidad e independencias. Ensayos sobre las representaciones hispánicas. MAPFRE/FCE: México.

Guerra, F. X. \& Lemperiere A. (1998). Los espacios públicos en Iberoamérica. Ambigüedades y problemas. Siglos XVIII - XIX. FCE: México.

Guerra, F. X. (1999). De lo uno a lo múltiple: dimensiones y lógicas de la Independencia. En McFarlane, A. y Posada Carbó, E. (comp.), Independence and Revolution in Spanish América: Perspectives and Problems. University of London: London.

Guerra, F. X. (1999). El soberano y su reino. Reflexiones sobre la génesis del ciudadano en América Latina. En Sábato, H. (coord.), Ciudadanía política y formación de las naciones. Perspectivas históricas de América Latina. FCE: México.

Hale, C. (1968). Mexican liberalism in the age of Mora, 1821 - 1853. New Haven y Londres: Yale University Press.

Halperin Donghi, T. (1982). José Luis Romero y su lugar en la historiografía nacional. En José Luis Romero (comp.). Las ideologías de la cultura nacional y otros ensayos (s/d). Buenos Aires: CEAL.

Koselleck, R. (1993). Futuro pasado: para una semántica de los tiempos históricos. Barcelona: Paidós.

Palti, J. E. (2005). De la historia de "ideas" a la historia de los "lenguajes políticos". Las escuelas recientes de análisis conceptual. El panorama latinoamericano. Anales, núm. $7-8,63-82$.

Palti, J. E. (2007). El tiempo de la política. El siglo XIX reconsiderado. Siglo venintiuno: Buenos Aires.

Palti, J. E. (2008). La invención de una legitimidad. Razón y retórica en el pensamiento mexicano del siglo XIX (Un estudio sobre las formas del discurso político). FCE: Buenos Aires.

Palti, J. E. (2009). El momento romántico. Nación, historia y lenguajes políticos en la Argentina del siglo XIX. Buenos Aires: Eudeba.

Pocock, J. G. A. (2011). Pensamiento político e historia. Ensayos sobre teoría y método. Madrid: Akal. 
Polgovsky Ezcurra, M. (2010). La historia intelectual latinoamericana en la era del giro lingüístico. Nuevo Mundo Mundos Nuevos, s/d. Recuperado en: http://nuevomundo.revues.org/60207

Rabasa Gamboa, E. (2011). La escuela de Cambridge: Historia del pensamiento político. Una búsqueda metodológica. En - claves del pensamiento, año V, núm. 9, 157 - 180. Silva, Mexicano.

Schwarz, R. (2000). As idéias fora do lugar. En Schwarz, R. Ao vencedor as batatas. Forma literária e processo social nos inicios do romance brasileiro (932). San Pablo: Livraria Duas Cidades.

Rosanvallon, P. (2002). Por una historia conceptual de lo político. Buenos Aires: FCE.

Silva R. (2009). Historia intelectual e teoría política. Revista de Sociología Política, 37(43), pp. $301-318$.

Silva, R. (2010). O contextualismo linguistico do pensamiento político: Quentin Skinner e o debate metodológico contemporáneo. Dados - Revista de Ciencias Sociales, vol. 53, num. 2, $299-335$.

Skinner, Q. (2007). Lenguaje, política e historia. Buenos Aires: UNQ.

Skinner, Q. (2008). Maquiavelo. Madrid: Alianza.

Skinner, Q. (1993). Los fundamentos del pensamiento político moderno. I. El renacimiento. México D. F.: FCE.

Skinner, Q. (1993). Los fundamentos del pensamiento político moderno. II. La reforma. México D. F.: FCE.

Vilanou, C. (2006). Historia conceptual e historia intelectual. Ars Brevis, 12, pp. $165-190$. 